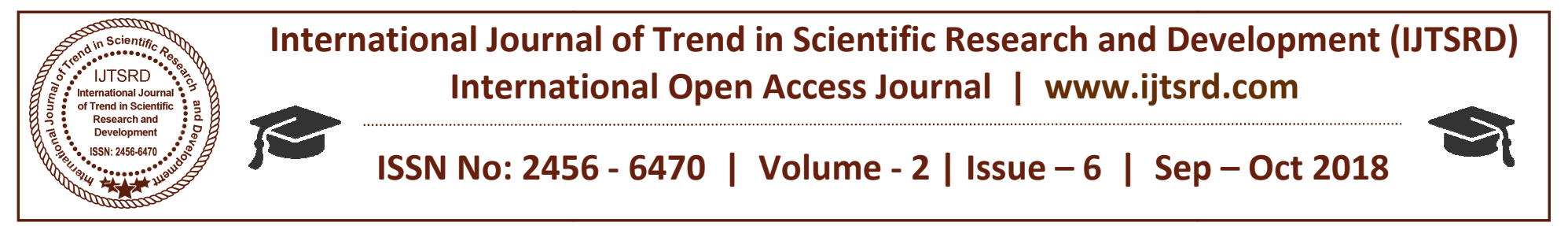

\title{
Educational Data Mining: A Blend of Heuristic and K-Means Algorithm to Cluster Students to Predict Placement Chance
}

\author{
Ashok. M. V ${ }^{1}$, G. Hareesh Kumar ${ }^{2}$ \\ ${ }^{1} \mathrm{M}$. Tech, ${ }^{2}$ Assistant Professor \\ Department of CSE, BIT Institute of Technology, Andhra Pradesh, India
}

\begin{abstract}
Educational data mining emphasizes on developing algorithms and new tools for identifying distinctive sorts of data that come from educational settings, to better understand students. The objective of this paper is to cluster efficient students among the students of the educational institution to predict placement chance. Data mining approach used is clustering. Ablend of heuristic and K-means algorithm is employed to cluster students based on KSA (knowledge, Communication skill and attitude). To assess the performance of the program, a student data set from an institution in Bangalore were collected for the study as a synthetic knowledge. A model is proposed to obtain the result. The accuracy of the results obtained from the proposed algorithm was found to be promising when compared to other clustering algorithms.
\end{abstract}

Keyword: Educational data mining, clustering, efficient student, heuristic, K-means, KSA concept

\section{INTRODUCTION}

Educational data mining (EDM) is the presentation of Data Mining (DM) techniques to educational data, and so, its objective is to examine these sorts of data in order to resolve educational research issues.

An institution consists of many students. For the students to get placed, he/she ought to have smart score in KSA. KSA is knowledge, communication skills and attitude. This is often one of the vital criteria used for choosing student for placement. It's also a proven fact that better placements end up in good admissions. All the students will not have high KSA score. Therefore, it's necessary to find those students who possess smart KSA and who don't. Therefore, there's a requirement for clustering to eliminate students who don't seem to be competent to be placed.

\section{PROBLEM STATEMENT}

Normally many students are there in institutions. It is a tedious task and time consuming to predict placement chance for all students and it's not necessary additionally to predict placement chance for those students who are incompetent academically. Therefore, there's a necessity for clustering the efficient students having smart KSA score whose placement chance may be predicted.

\section{RELATED WORKS}

Performance appraisal system is basically an interaction between an employee and also the supervisor or management and is periodically conducted to identify the areas of strength and weakness of the employee. The objective is to be consistent regarding the strengths and work on the weak areas to boost performance of the individual and therefore accomplish optimum quality of the process. [8]. (Chein and Chen, 2006 [9] Pal and Pal, 2013[10]. Khan, 2005 [11], Baradwaj and Pal, 2011 [12], Bray [13], 2007, S. K. Yadav et al., 2011[14]. K-means is one amongst the best and accurate clustering algorithms. This has been applied to varied issues. Kmeans approach cut samples apart into $\mathrm{K}$ primitive clusters. This approach or technique is particularly appropriate once the quantity of observations is huge or the file is gigantic. Wu, 2000 [1]. K-means method is wide utilized in segmenting markets. (Kim et al., 2006[2]; Shin \&amp; Sohn, 2004 [3]; Jang et al., 2002[4]; Hruschka \& amp; natter, 1999[5]; K-means cluster may be a variation of $\mathrm{k}$-means cluster that refines cluster assignments by repeatedly making an attempt to subdivide, and keeping the simplest 
ensuing splits, till some criterion is reached. Dan pelleg, andrewMore, K-means: Extended K-means which is an effective Estimation of the quantity of Clusters [6], Thomas aloe, Remi Servien, The K-Alter algorithm: a parameter-free method to perform unsupervised clustering [7].

\section{METHODOLOGY}

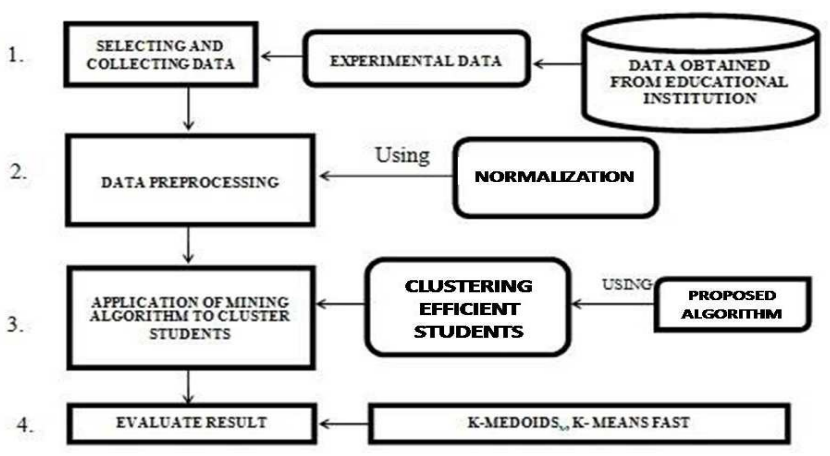

Fig 1: Proposed Methodology

Concept and research framework

The methodology along with its computational processes for determining the efficient student, is outlined below:

\section{Step 1: Data collection.}

The goal is to identify proficient students within the college under consideration viz., KK for the year 2017-18.The students hail from numerous courses. The courses are MBA, MCA, BCA, B.Com, and BBA.

Step 2: Data pre-processing using normalization In our study, the attribute 'percent' is measured in (\%) and 'skill' using numbers starting from [1 to 10]. In our study percentage (\%) prevails on skills. Therefore, there's a necessity for standardization or normalization.

\section{Step 3: Proposed Clustering technique}

This step clusters efficient students among all the students of the institution using proposed clustering algorithm.

Step 4: Evaluate the result

\section{DATA DESCRIPTION}

Table 1: Database Description

\begin{tabular}{|l|l|l|}
\hline \multicolumn{1}{|c|}{ Variables } & \multicolumn{1}{c|}{ Description } & Possible Values \\
\hline Stu id & Id of the student & $\{$ Int $\}$ \\
\hline Name & Name of the Student alfCh and & $\{$ TEKT $\}$ \\
\hline Sub & Subject Name eVe lopment & $\{$ TEKT $\}$ \\
\hline M1, M2, M3, M4... & Marks scored in each subject & $\{1,2,3,4,5 \ldots 100\}$ \\
\hline T in \% & Total marks SN: 2456-6470 & $\{1 \%-100 \%\}$ \\
\hline Skill & (Communication skills+Attitude) score out of 10 & $\{1,2,3,4,5 \ldots 10\}$ \\
\hline Min & Minimum Marks for passing a subject & 32 \\
\hline Max & Maximum Marks for passing a subject & 100 \\
\hline
\end{tabular}

Stu_Id:- ID of the student. It can take any integer values.

Name: - Name of the student.

Sub: - $\quad$ represents the name of the topic. It will take solely the values starting from A-Z.

M1, M2, M3..:-various subject marks scored by a student. It will take solely the numeric values from 0 to 100 .

$\mathrm{T}:-\quad \quad \quad$ total marks scored by every student depicted within the form percentage i.e., $1 \%$ to $100 \%$.

Skill: - Communication and attitude score out of ten

Min: - $\quad$ Minimum marks for passing a subject

Max: - maximum marks for passing a subject 


\section{EXPERIMENTAL EVALUATION}

Step 1: Data collection

Table 2: Input Table

\begin{tabular}{|c|c|c|c|c|c|c|c|}
\hline \multirow{3}{*}{$\begin{array}{c}\text { Stu id } \\
\text { Name } \\
\text { Sub }\end{array}$} & & & \multirow{2}{*}{$\frac{1}{\text { Vikas }}$} & \multirow{2}{*}{$\frac{2}{\text { Guru }}$} & \multirow{2}{*}{$\frac{3}{\text { Sayed }}$} & \multirow{2}{*}{$\frac{4}{\text { Deepak }}$} & \multirow{2}{*}{$\begin{array}{l}\ldots \\
\ldots \\
\ldots\end{array}$} \\
\hline & & & & & & & \\
\hline & Min & MaK & M1 & M2 & M3 & M4 & M5 \\
\hline $\mathbf{C a}$ & 32 & 100 & 20 & 98 & 45 & 92 & \\
\hline $\mathbf{B i}$ & 32 & 100 & 23 & 98 & 69 & 83 & \\
\hline Java & 32 & 100 & 24 & 97 & 67 & 74 & *.. \\
\hline Se & 32 & 100 & 25 & 96 & 89 & 92 & 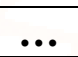 \\
\hline $\mathbf{C f}$ & 32 & 100 & 26 & 95 & 88 & 88 & ... \\
\hline $\mathbf{D b}$ & 32 & 100 & 28 & 90 & 56 & 81 & ... \\
\hline$\ldots$ & $\cdots$ & $\cdots$ & $\ldots$ & $\ldots$ & $\ldots$ & $\ldots$ & $\ldots$ \\
\hline $\mathrm{T}$ in $\%$ & & & 25 & 90 & 65 & 80 &. \\
\hline Skill & & & & 9 & 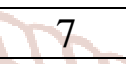 & 8 & \\
\hline
\end{tabular}

Fields or variables listed higher than Marks scored in selected subjects for the year 2017-18 is considered and collected from an institution in city.

Step 2: Data Pre-processing:

Pre-processing is done using Normalization.

Table 3: Pre-processed table

\begin{tabular}{|c|c|c|c|c|c|}
\hline Stu id & $\mathbf{1}$ & $\mathbf{2}$ & $\mathbf{3}$ & $\mathbf{4}$ & $\ldots$ \\
\hline Sub & $\mathbf{M 1}$ & $\mathbf{M 2}$ & $\mathbf{M 3}$ & $\mathbf{M 4}$ & $\mathbf{M 5}$ \\
\hline $\mathbf{C a}$ & 20 & 98 & 45 & 92 & $\ldots$ \\
\hline $\mathbf{B i}$ & 23 & 98 & 69 & 83 & $\ldots$ \\
\hline Java & 24 & 97 & 67 & 74 & $\ldots$ \\
\hline Se & 25 & 96 & 89 & 92 & $\ldots$ \\
\hline $\mathbf{C f}$ & 26 & 95 & 88 & 88 & $\ldots$ \\
\hline Db & 28 & 90 & 56 & 81 & $\ldots$ \\
\hline$\ldots$ & $\ldots$ & $\ldots$ & $\ldots$ & $\ldots$ & $\ldots$ \\
\hline $\begin{array}{c}\text { T in } \\
\text { \% }\end{array}$ & 25 & 90 & 65 & 80 & $\ldots$ \\
\hline Skill & 7 & 9 & 7 & 8 & $\ldots$ \\
\hline
\end{tabular}

Steps of the proposed algorithm are explained below:

Step 1: Clustering using proposed algorithm.

Step 1.1: Pre-processed table are going to be the input.

Step 1.2: Cluster efficient students and determine the precise number of clusters. K-value is calculated using heuristic method by incrementing the $\mathrm{K}$-value in each step by one and the results are shown below.

Partition of ECS is finished at first by taking $\mathrm{K}=2$

After Applying proposed algorithm with $\mathrm{K}=2$, we've got
Table- 4: Partial view of clusters of students, for $K=2$

\begin{tabular}{|c|c|}
\hline Cluster 1 & Cluster 2 \\
\hline 1 & 2 \\
\hline 10 & 3 \\
\hline 11 & 4 \\
\hline 12 & 5 \\
\hline 13 & 6 \\
\hline 16 & 7 \\
\hline 18 & 8 \\
\hline 21 & 9 \\
\hline 22 & 14 \\
\hline 24 & 15 \\
\hline 26 & 17 \\
\hline 27 & 19 \\
\hline 29 & 20 \\
\hline 30 & 23 \\
\hline & 25 \\
\hline & 28 \\
\hline
\end{tabular}

The above table 4 shows the grouping of students into two groups.

Table - 5: Difference between clusters for $K=2$

\begin{tabular}{|c|c|c|}
\hline Cluster & Cluster1 & Cluster2 \\
\hline Custer 1 & 0 & 0.229 \\
\hline Custer 2 & 0.229 & 0 \\
\hline
\end{tabular}

For $\mathrm{K}=2$, group distances are tabulated. In this rounded value 0.23 is the minimum.

Applying K-means for $\mathrm{k}=3$, we've the subsequent results. 
International Journal of Trend in Scientific Research and Development (IJTSRD) ISSN: 2456-6470

Table- 6: Partial view of three clusters, for $K=3$ Cluster1 Cluster2

\begin{tabular}{|c|c|}
\hline 1 & 2 \\
\hline 10 & 3 \\
\hline 11 & 4 \\
\hline 12 & 5 \\
\hline 13 & 6 \\
\hline 16 & 7 \\
\hline 18 & 8 \\
\hline 21 & 9 \\
\hline 22 & 14 \\
\hline 24 & 15 \\
\hline 26 & 17 \\
\hline 27 & 19 \\
\hline 29 & 20 \\
\hline 30 & 23 \\
\hline & 25 \\
\hline & 28 \\
\hline
\end{tabular}

\begin{tabular}{|l|l|l|}
\hline Cluster 1 & Cluster 2 & Cluster 3 \\
\hline
\end{tabular}

\begin{tabular}{|c|c|c|}
\hline 1 & 9 & 2 \\
\hline 10 & 24 & 3 \\
\hline 11 & & 4 \\
\hline 12 & & 5 \\
\hline 13 & & 6 \\
\hline 16 & & 7 \\
\hline 18 & & 8 \\
\hline 21 & & 14 \\
\hline 22 & & 15 \\
\hline 26 & & 17 \\
\hline 27 & & 19 \\
\hline 29 & & 20 \\
\hline 30 & & 23 \\
\hline & & 25 \\
\hline & & 28 \\
\hline
\end{tabular}

The above table- 6 indicates the partial view of 3 clusters.

Table- 7: Differences between clusters

\begin{tabular}{|c|c|c|c|}
\hline Cluster & Cluster1 & Cluster2 & Cluster3 \\
\hline Custer 1 & 0 & 0.116 & 0.165 \\
\hline Custer 2 & 0.116 & 0 & 0.154 \\
\hline Custer 3 & 0.165 & 0.154 & 0 \\
\hline
\end{tabular}

For $\mathrm{K}=3$, the distance between the groups are tabulated. In this 0.12 (rounded) is the minimum value

For $\mathrm{K}=4$; we have the following results.
Table- 8: Partial view of four clusters, for $K=4$ \begin{tabular}{|c|c|c|c|}
\hline Cluster 1 & Cluster 2 & Cluster 3 & Cluster 4 \\
\hline
\end{tabular}

\begin{tabular}{|l|c|c|c|}
\hline 1 & 9 & 3 & 2 \\
\hline & 10 & 4 & \\
\hline & 11 & 5 & \\
\hline & 12 & 6 & \\
\hline & 13 & 7 & \\
\hline & 16 & 8 & \\
\hline & 18 & 14 & \\
\hline & 21 & 15 & \\
\hline & 22 & 17 & \\
\hline & 24 & 19 & \\
\hline & 26 & 20 & \\
\hline & 27 & 23 & \\
\hline & 29 & 25 & \\
\hline & 30 & 28 & \\
\hline & & & \\
\hline
\end{tabular}

Table-9: Comparison of distance between the clusters

\begin{tabular}{|c|c|c|c|c|}
\hline Cluster & $\begin{array}{c}\text { Cluster } \\
\mathbf{1}\end{array}$ & $\begin{array}{c}\text { Cluster } \\
\mathbf{2}\end{array}$ & $\begin{array}{c}\text { Cluster } \\
\mathbf{3}\end{array}$ & $\begin{array}{c}\text { Cluster } \\
\mathbf{4}\end{array}$ \\
\hline $\begin{array}{c}\text { Custer } \\
\mathbf{1}\end{array}$ & 0 & 0.104 & 0.187 & 0.342 \\
\hline $\begin{array}{c}\text { Custer } \\
\mathbf{2}\end{array}$ & 0.104 & 0 & 0.083 & 0.238 \\
\hline $\begin{array}{c}\text { Custer } \\
\mathbf{3}\end{array}$ & 0.187 & 0.083 & 0 & 0.154 \\
\hline $\begin{array}{c}\text { Custer } \\
\mathbf{4}\end{array}$ & 0.342 & 0.238 & 0.154 & 0 \\
\hline
\end{tabular}

Comparative table given above displays the distance between the clusters. Table - 9 compares the two clusters in terms of distance between them. Cluster 3cluster $1=0.187$ given in row 1 column 4.Similarly, the other values are calculated. This table is the resultant of application of Proposed Algorithm, incrementing value of $\mathrm{K}$ in every step by 1 .

Table- 10: Cluster distance table

\begin{tabular}{|c|c|}
\hline Number of clusters & The short Cluster distance \\
\hline Cluster 2 & 0.2293 \\
\hline Cluster 3 & 0.1658 \\
\hline Cluster 4 & 0.3428 \\
\hline Cluster 5 & 0.3133 \\
\hline
\end{tabular}

The first value 0.2293 within the shorter cluster distance field represents the distance between the cluster 1 and 2, similarly the second value viz., 0.1658 represents the gap between 1 and 3 . The opposite values within the table are often interpreted similarly. 
means of cluster-based market segmentation. European Journal of Operational Research, 114(3), 346-353.

5. Leon Bottou, YoshuaBengio, "Convergence Properties of the K-Means Algorithms", Advances in Neural Information Processing Systems 7, 1995.

6. Dan pelleg, Andrew Moree,"K-means: EKtending $\mathrm{K}$ - means with Efficient Estimation of the Number of Clusters"

7. Thomas Laloe, Remi Servien, "The K-Alter algorithm : a parameter-free method to perform unsupervised clustering"

8. Archer-North and Associates, "Performance Appraisal", http://www.performanceappraisal.com, 2006, Accessed Dec, 2012.

9. Chein, C., Chen, L., "Data mining to improve personnel selection and enhance human capital: A case study in high technology industry", EKpert Systems with Applications, In Press (2006).

10. K. Pal, and S. Pal, "Analysis and Mining of Educational Data for Predicting the Performance of Students"(IJECCE) International Journal of Electronics Communication and Computer Engineering, Vol. 4, Issue 5, pp. 1560-1565, ISSN: 2278-4209, 2013.

11. Z. N. Khan, "Scholastic achievement of higher secondary students in science stream", Journal of Social Sciences, Vol. 1, No. 2, pp. 84-87, 2005.

12. B.K. Bharadwaj and S. Pal. "Mining Educational Data to Analyze Students' Performance", International Journal of Advance Computer Science and Applications (IJACSA), Vol. 2, No. 6, pp. 63-69, 2011.

13. M. Bray, The shadow education system: private tutoring and its implications for planners, (2nd ed.), UNESCO, PARIS, France, 2007.

14. S. K. Yadav, B.K. Bharadwaj and S. Pal, "Data Mining Applications: A comparative study for Predicting Student's Performance", International Journal of Innovative Technology and Creative Engineering (IJITCE), Vol. 1, No. 12, pp. 13-19, 2011. 